\title{
Effect of temperature on the shear strength of aluminium single lap bonded joints for high temperature applications
}

\author{
M.D. Banea, L.F.M. da Silva and R.D.S.G. Campilho
}

\begin{abstract}
An experimental and numerical investigation into the shear strength behaviour of adhesive single lap joints (SLJs) was carried out in order to understand the effect of temperature on the joint strength. The adherend material used for the experimental tests was an aluminium alloy in the form of thin sheets, and the adhesive used was a high-strength high temperature epoxy. Tensile tests as a function of temperature were performed and numerical predictions based on the use of a bilinear cohesive damage model were obtained. It is shown that at temperatures below $T_{\mathrm{g}}$, the lap shear strength of SLJs increased, while at temperatures above $T_{\mathrm{g}}$, a drastic drop in the lap shear strength was observed. Comparison between the experimental and numerical maximum loads representing the strength of the joints shows a reasonably good agreement.
\end{abstract}

Keywords: high temperature adhesives; single lap joints; temperature tests; cohesive zone model

\section{Introduction}

The influence of temperature on the strength of adhesive joints is an important factor to consider in the design of adhesive joints. The most significant factors that determine the strength of an adhesive joint when used over a wide temperature range are: the cure shrinkage [1], the coefficients of thermal expansion (CTE), (especially when compared to the CTE of the substrates) [2] and different adhesive mechanical properties with temperature such as the stressstrain curve and the toughness [3-8]. However, due to the polymeric nature of adhesives, the variation of the mechanical properties of the adhesives with temperature is generally the most important factor to consider when designing a bonded joint.

Studies that present experimental results of adhesive joints with structural adhesives (especially epoxies) as a function of temperature generally show a decrease in strength with increasing and decreasing temperatures [9-15]. At high temperatures the cause is the lower adhesive strength, while at low temperatures the high thermal stresses and the brittleness of the adhesive are the origin of such behaviour. Adams et al. [10] studied the performance of single lap joints (SLJs) with epoxy adhesives at low and room temperatures. They investigated the effects of adherend mismatch, shrinkage and adhesive properties on the stress state of lap joints and 
found that the stresses caused by adhesive shrinkage have much less effect on the lap joint strength than those generated by the adherend thermal mismatch. Banea and da Silva [5] tested SLJs with an epoxy adhesive at $-40{ }^{\circ} \mathrm{C}$, room temperature (RT) and $80^{\circ} \mathrm{C}$, and showed that the lap shear strength of the adhesive joints tested at $80^{\circ} \mathrm{C}$ decreased by approximately $30 \%$ than that of the specimens tested at RT and by approximately $10 \%$ at $-40{ }^{\circ} \mathrm{C}$.

Temperature also affects the fracture behaviour of adhesive joints [16-18]. Banea et al. [17] used the double cantilever beam (DCB) test to evaluate the temperature dependence of the fracture toughness for adhesive joints bonded with a high temperature RTV silicone adhesive, covering a range of temperatures between RT to $260^{\circ} \mathrm{C}$. They concluded that the value of toughness and the traction-separation laws exhibited strong temperature dependence. Actually, the value of fracture toughness, the peak cohesive stress and the respective end-opening displacement all decreased with temperature. More recently, Banea et al. [18] performed an experimental and numerical study to evaluate the effect of temperature on the mode I fracture toughness of a high temperature epoxy adhesive. They found that the fracture toughness of the epoxy adhesive investigated was essentially temperature independent below the $T_{\mathrm{g}}$ $\left(T_{\mathrm{g}} \approx 155^{\circ} \mathrm{C}\right.$ ); while above the $T_{\mathrm{g}}$ of the adhesive (at $200^{\circ} \mathrm{C}$ ), a drastic drop in fracture toughness was observed. However, the properties of adhesives over the range of service temperatures need to be studied for each type of application. The adhesives for aerospace applications need to withstand high temperatures, typically in excess of $150{ }^{\circ} \mathrm{C}$.

In this study, aluminium SLJs were tested at RT and high temperatures $(100,125,150$, 175 and $200{ }^{\circ} \mathrm{C}$ ). The behaviour of the joints was examined both experimentally and numerically. A bilinear cohesive damage model was used to obtain the numerical predictions as a function of temperature.

\section{Experimental}

\subsection{Adhesive selected}

The adhesive investigated in this study was a one-component high temperature paste epoxy adhesive XN1244, supplied by Nagase ChemteX (Japan).

A key parameter in the testing of adhesive joints is the glass transition temperature $\left(T_{\mathrm{g}}\right)$ of the adhesive. When the adhesively bonded joints were tested below this temperature, the adhesive behaved like a low-strain rigid material while above this temperature the adhesive had a more rubber-like behaviour. The $T_{\mathrm{g}}$ of $\mathrm{XN1244}$ adhesive obtained by dynamical mechanical thermal analysis method was approximately $155^{\circ} \mathrm{C}[19]$.

The characterization tests for the adhesive were carried out under tension (mode I loading) and shear (mode II loading) considering three specimens for each condition, which allowed determination of yield strengths and moduli in both loadings. The tensile properties (mode I loading) of XN1244 adhesive were determined using dogbone specimens, produced from bulk adhesive plates cured in a steel mould, using a silicone rubber frame, according to the French standard NF T 76-142 [20]. Curing of the bulk plates was carried out in a hot press $\left(1 \mathrm{~h}\right.$ at $\left.140{ }^{\circ} \mathrm{C}\right)$. The XN1244 specimens were tested in tension using a universal testing machine Shimadzu ${ }^{\circledR}$ model AUTOGRAPH, under a constant crosshead rate of $1 \mathrm{~mm} / \mathrm{min}$. Strains were measured by a video extensometer Messphysik ME46, along a length of $50 \mathrm{~mm}$ between hand-painted marks. For the high temperatures, the environmental chamber of the machine was used to reach the desired temperature. Figure 1 illustrates representative XN1244 adhesive tensile stress-strain curves as a function of temperature obtained from tensile tests, which show a decrease in XN1244 adhesive strength with increasing temperature and an increase in the ductile response of the adhesive. The 


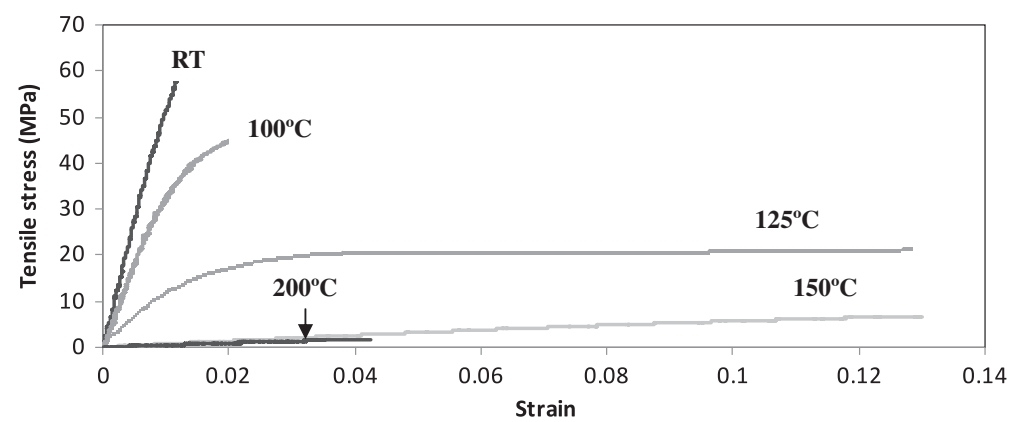

Figure 1. Tensile stress-strain $(\sigma-\varepsilon)$ curves from representative tensile bulk tests on adhesive XN1244 as a function of temperature.

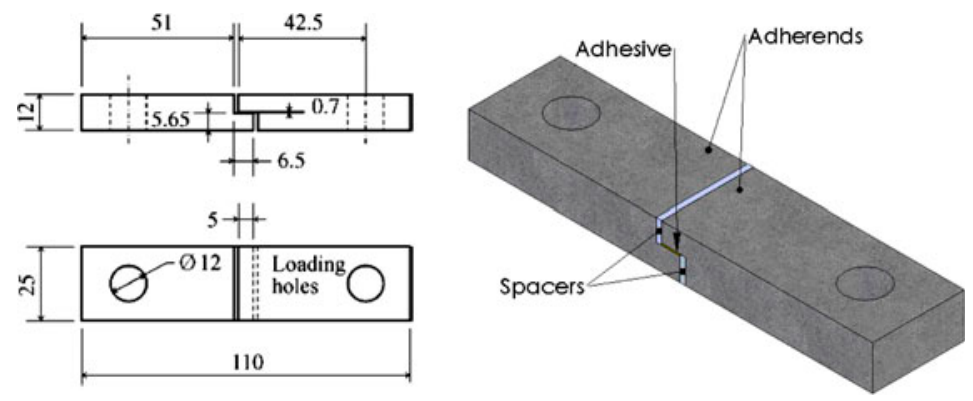

Figure 2. Standard TAST specimen (dimensions in $\mathrm{mm}$ ).

characterization of the mechanical properties of XN1244 adhesive has been described in more detail elsewhere [19].

The thick adherend shear test (TAST) tests for mode II loading followed the guidelines of the standard ISO 11003-2:1999 [21], using steel substrates of dimensions $110 \mathrm{~mm} \times$ $25 \mathrm{~mm} \times 12 \mathrm{~mm}$ (Figure 2). The joint surfaces were grit blasted and degreased with acetone prior to application of the adhesive. The bondline thickness was nominally $0.7 \mathrm{~mm}$ and the length of the overlap test section was $5 \mathrm{~mm}$. Two spacers $(1.5 \mathrm{~mm}$ thick) were inserted in the gaps between the adherends after the application of the adhesive and prior to curing in order to provide the necessary spacing between the two adherends. These spacers were removed after the adhesive was cured. The joints were cured in a hot press following the manufacturer's suggested curing conditions $\left(1 \mathrm{~h}\right.$ at $\left.140^{\circ} \mathrm{C}\right)$. TAST tests were performed at RT on an MTS servohydraulic machine, model 312.31 , at a constant crosshead rate of $0.1 \mathrm{~mm} / \mathrm{min}$. The displacement was measured with two methods: a $25 \mathrm{~mm}$ length MTS extensometer and a non-contact method (video microscopy). As the extensometer is mounted on the metallic substrate, the extensometer measures not only the displacement of the adhesive, but also the displacement of the adherend [22]. Therefore, it is necessary to apply a correction to the measured displacements. At the same time, video microscopy was used to record the displacements, which gives only the adhesive displacement. The strains were calculated using the spatial correlation method developed by Chousal and Gomes [23].

A characteristic shear stress-strain curve of XN1244 adhesive measured by the two methods (MTS extensometer and video microscopy) at RT is shown in Figure 3. The shear modulus was determined from the stress-strain curve measured by the video microscopy method 


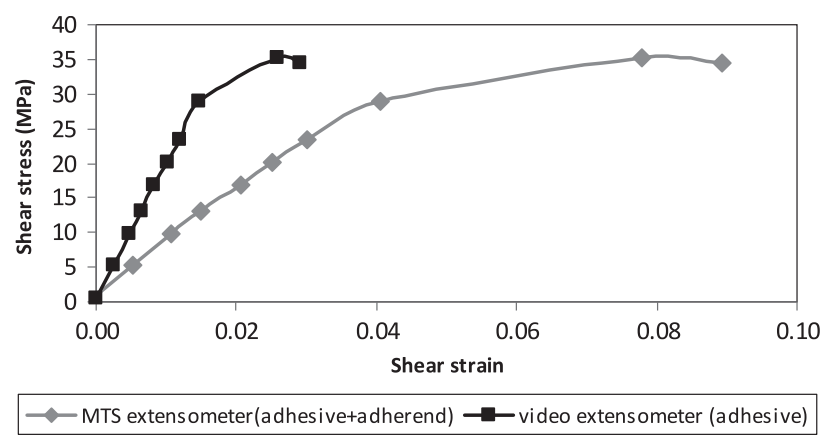

Figure 3. Typical XN1244 adhesive shear stress-strain curve measured by the two methods (MTS extensometer and video microscopy).

(the 'adhesive' curve). The shear strength is coincident for the two curves. The shear strain to failure presented in Table 1 was obtained from the 'steel+adhesive' curve, because it is not always possible to obtain the last part of the curve by spatial correlation due to image focusing problems at break point.

Table 1 summarizes the data collected on this adhesive, which were subsequently used for the finite element simulations and strength predictions. The yield strength was calculated for a plastic deformation of $0.2 \%$.

\subsection{Specimens fabrication}

Aluminium alloy 6082-T651 (Al Si1MgMn) substrates characterized by a high tensile strength with a thickness of 3 and $25 \mathrm{~mm}$ width were used in order to avoid plastic deformation of the adherends. The bulk stress-strain $(\sigma-\varepsilon)$ response of the aluminium adherends, obtained according to ASTM-E8M-04 standard [24], is presented in Figure 4 for the three specimens tested [25]. The aluminium has a Young's modulus of $70.07 \pm 0.83 \mathrm{GPa}$, a yield stress of $261.67 \pm 7.65 \mathrm{MPa}$, a maximum strength of $324 \pm 0.16 \mathrm{MPa}$ and a failure strain of $21.70 \pm 4.24 \%$. The bilinear approximation of Figure 4 was used as input in the simulations.

The joint surfaces were grit blasted and degreased with acetone prior to the application of the adhesive. The substrates were bonded and then the specimens were cured in a hot press following the manufacturer's suggested curing conditions $\left(1 \mathrm{~h}\right.$ at $\left.140^{\circ} \mathrm{C}\right)$. A mould with spac-

Table 1. Properties of XN1244 adhesive.

\begin{tabular}{lr}
\hline Property & Value \\
\hline Young's modulus, $E(\mathrm{GPa})$ & $5.87 \pm 0.33$ \\
Poisson's ratio, $v^{\mathrm{a}}$ & 0.35 \\
Tensile yield strength, $\sigma_{\mathrm{y}}(\mathrm{MPa})$ & $46.90 \pm 2.70$ \\
Tensile failure strength, $\sigma_{\mathrm{f}}(\mathrm{MPa})$ & $68.23 \pm 5.06$ \\
Tensile failure strain, $\varepsilon_{\mathrm{f}}(\%)$ & $1.46 \pm 0.23$ \\
Shear modulus, $G(\mathrm{GPa})$ & $2.15 \pm 0.10$ \\
Shear failure strength, $\tau_{\mathrm{f}}(\mathrm{MPa})$ & $31.61 \pm 2.83$ \\
Shear failure strain, $\gamma_{\mathrm{f}}(\%)$ & $8.05 \pm 1.2$ \\
\hline
\end{tabular}

a'Manufacturer's data. 


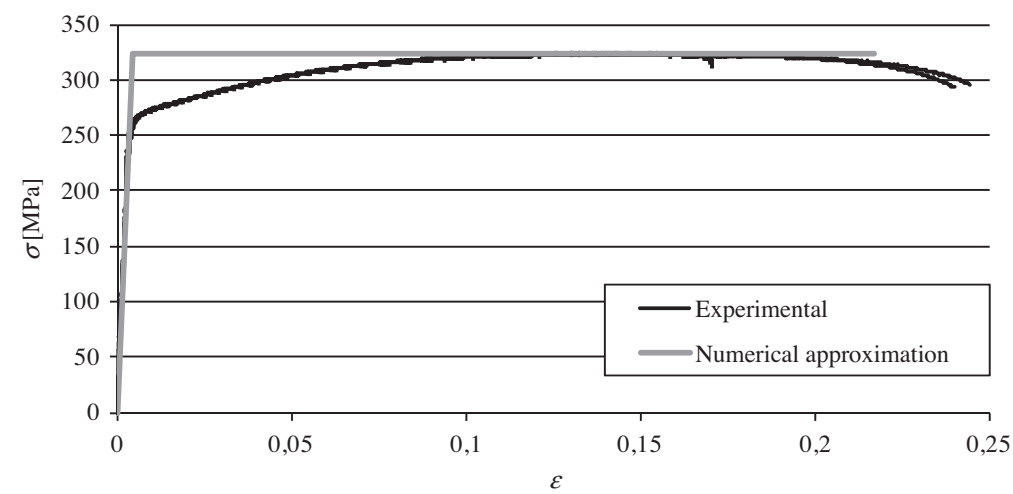

Figure 4. Experimental tensile stress-strain $(\sigma-\varepsilon)$ curves for the aluminium AW6082 T651 and approximation for the FEM analysis.

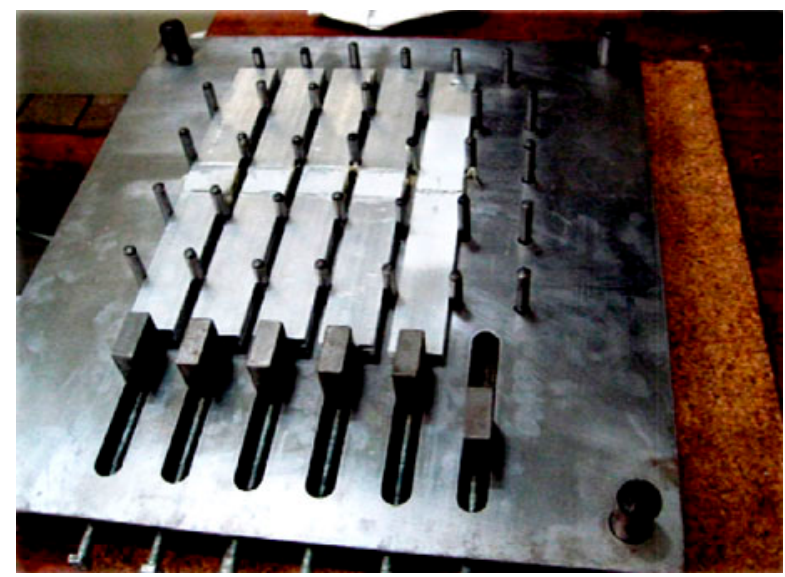

Figure 5. Mould for SLJ specimens fabrication.

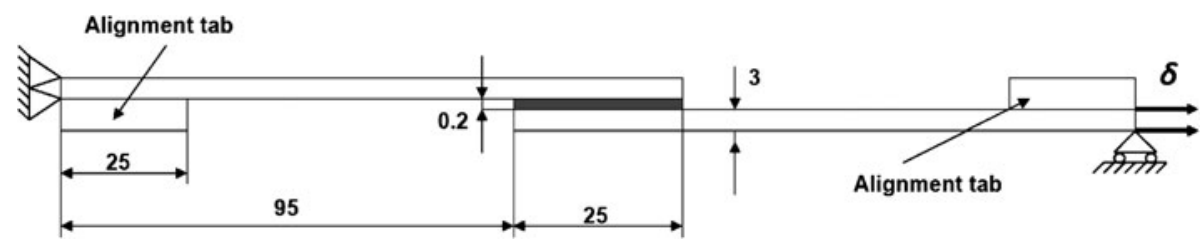

Figure 6. SLJ specimen geometry (dimensions in $\mathrm{mm}$ ).

ers for correct alignment of the substrates was used (see Figure 5). The bondline thickness was controlled using shims. The bondline thickness was $0.2 \mathrm{~mm}$ and the length of the overlap was $25 \mathrm{~mm}$. The geometry of the lap shear joint specimens used is shown in Figure 6 . 
Aluminium tabs were glued at the specimen's edges for a correct alignment in the testing machine.

\subsection{Test method}

The SLJs were tested at RT and high temperatures (100, 125, 150, 175 and $\left.200^{\circ} \mathrm{C}\right)$ using a universal testing machine Instron ${ }^{\circledR}$ model 8801 (Instron Co., USA), under a constant crosshead rate of $1 \mathrm{~mm} / \mathrm{min}$. For the high temperature tests, the environmental chamber of the machine was used to attain the desired test temperatures.

At least three joints were tested to failure at each temperature. For each joint tested, loaddisplacement curves were produced.

A thermocouple was applied to the specimen in order to ensure that the air temperature inside the chamber was equal to the specimen temperature. The tests were always performed

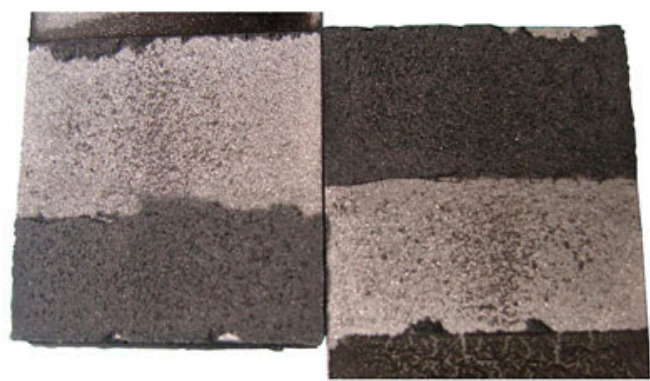

(a)

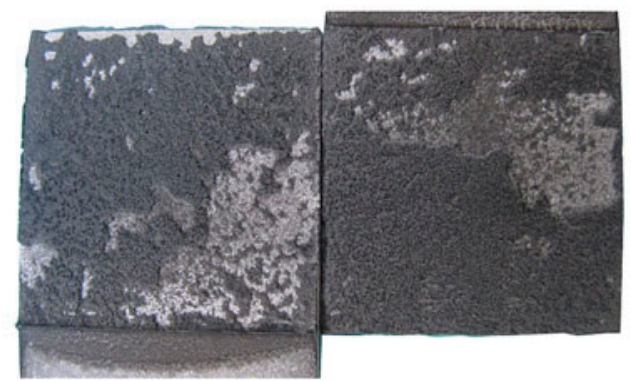

(c)

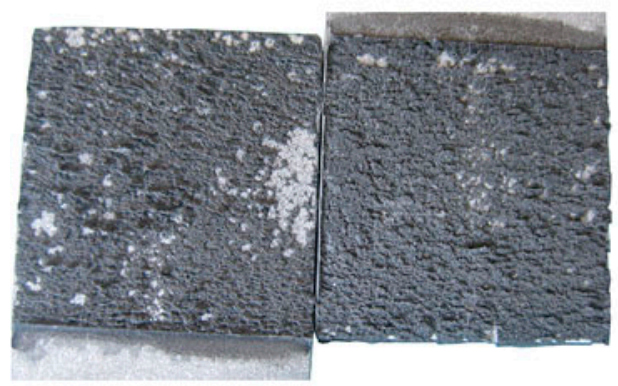

(e)

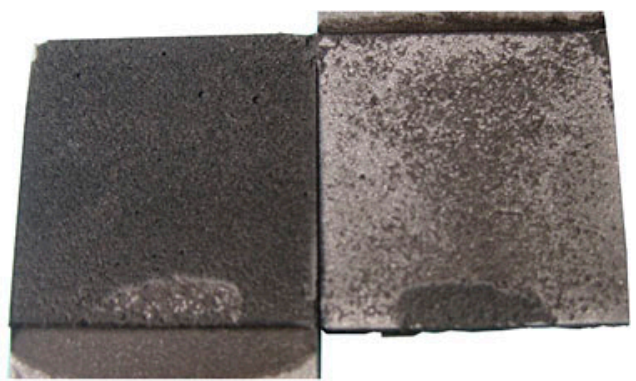

(b)

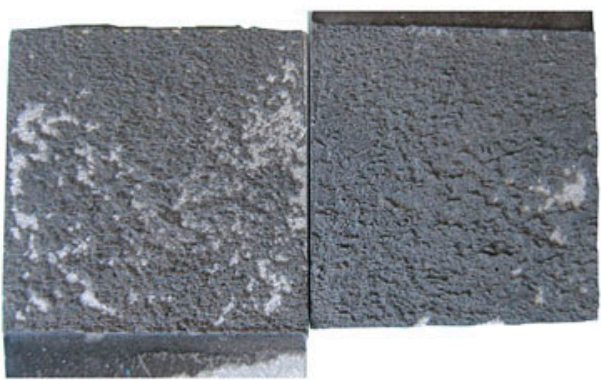

(d)

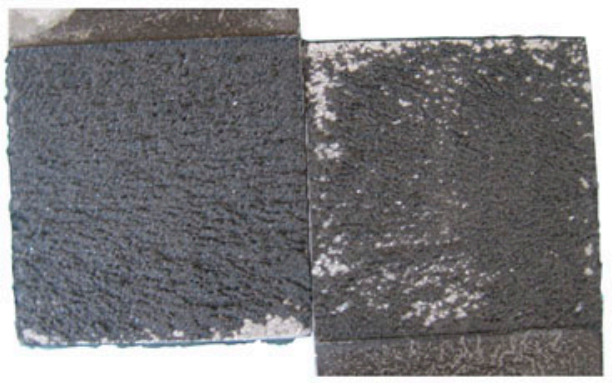

(f)

Figure 7. Failure mode of SLJs tested at (a) RT, (b) 100, (c) 125 , (d) 150 , (e) 175 and (f) $200^{\circ} \mathrm{C}$. 
after approximately $5 \mathrm{~min}$ of achieving the test temperature in the specimens, to ensure a steady state temperature throughout the specimen prior to testing.

\section{Experimental results}

\subsection{Failure modes}

After the tests, the failure modes of the specimens were evaluated visually. It is well known that for brittle adhesives the failure of the adhesive joints is dominated by stress concentrations [26]. Thus, at RT, failure of the adhesive occurs in regions of maximum stress or strain concentration. However, increasing the temperature, the adhesive becomes more ductile and there was a larger adhesive yielding which resulted in a change in failure mode. At RT, cracks which run through the adhesive close to the adherend-adhesive interface meet at the middle of the overlap as can be seen in Figure 7(a). For SLJs tested at $100^{\circ} \mathrm{C}$ (Figure 7(b)), the failure surface was different from that observed at RT in that main part of the adhesive inside the overlap remain on one of the adherends (there was a thin film left on the other adherend). For SLJs tested at $125^{\circ} \mathrm{C}$, the failure mode was a cohesive failure in the middle of the adhesive layer (Figure 7(c)). A similar failure mode occurred at the other temperatures (see Figure $7(\mathrm{~d})-(\mathrm{f})$ ). The failure surface at 175 and $200^{\circ} \mathrm{C}$ was rougher which indicates a higher plastic deformation of the adhesive.

\subsection{Effect of temperature}

Representative load-displacement curves of XN1244 adhesive SLJs as a function of temperature are presented in Figure 8. It can be seen that the failure load increased with temperature up to $150^{\circ} \mathrm{C}$, and decreased at 175 and $200^{\circ} \mathrm{C}$ as the $T_{\mathrm{g}}$ of the adhesive is overpassed. The XN1244 SLJs stiffness does not vary substantially with temperature up to $175^{\circ} \mathrm{C}$.

Average lap shear strengths and failure displacements of XN1244 SLJ as a function of temperature are presented in Figure 9. The average lap shear strength $\left(\tau_{\text {av }}\right)$ is given by:

$$
\tau_{\mathrm{av}}=P / b L
$$

where $P$ is the maximum load, $b$ is the joint width and $L$ is the joint overlap length.

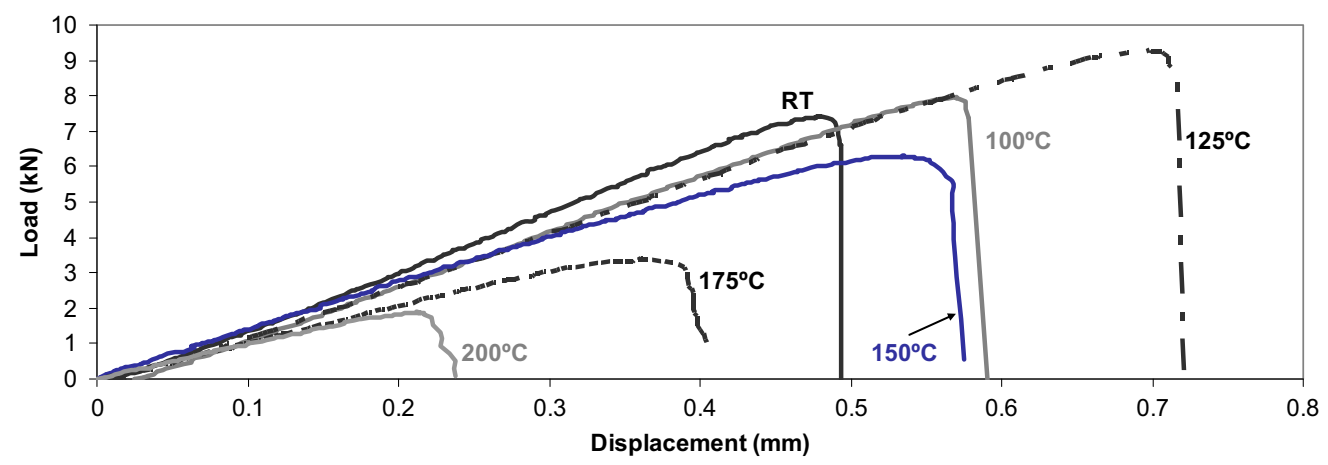

Figure 8. Representative load-displacement curves of XN1244 adhesive SLJs as a function of temperature. 


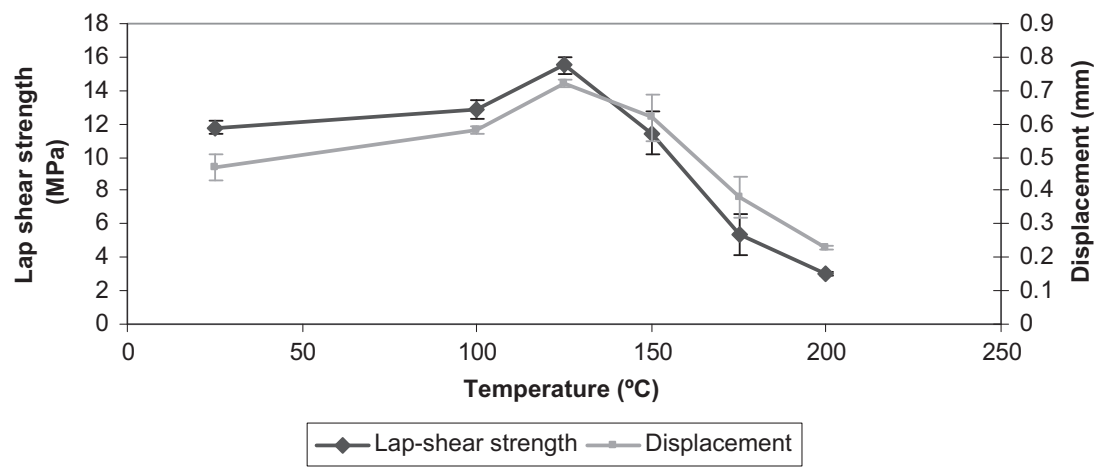

Figure 9. Average lap shear strength and displacement of $\mathrm{XN1244}$ adhesive as a function of temperature.

With an increase of temperature, a slight increase in lap shear strength occurs at $100^{\circ} \mathrm{C}$. The lap shear strength of the adhesive joints tested at $100^{\circ} \mathrm{C}$ was approximately $9 \%$ higher than that of specimens tested at RT. Data obtained from tests at $125^{\circ} \mathrm{C}$ showed an increase in lap shear strength of the adhesive by approximately $30 \%$. This can be explained by the fact that at RT, the failure takes place at the end of the overlap and once a crack has initiated, the adhesive has no ductility to absorb the fracture energy; while as the temperature increased and moved closer to the adhesive $T_{\mathrm{g}}\left(155^{\circ} \mathrm{C}\right)$, the adhesive became ductile and the overlap contributed more to the strength as the adhesive yields. The yielding of the adhesive redistributed the stresses, making more use of the less-strained parts of the overlap. In other words, joint strength depends not only on the peak values of the stresses, but also on the quantity of material that was exposed to these stresses. The decrease in stress peaks and increase in the amount of material subjected to stresses seemed to attain an optimum resulting in maximum joint strength at around $125^{\circ} \mathrm{C}$. This type of behaviour was similar to that observed by da Silva et al. in [27].

Generally, as the temperature was increased, the adhesive strength decreased and the ductility increased. There is a temperature when the adhesive starts to behave like a rubber

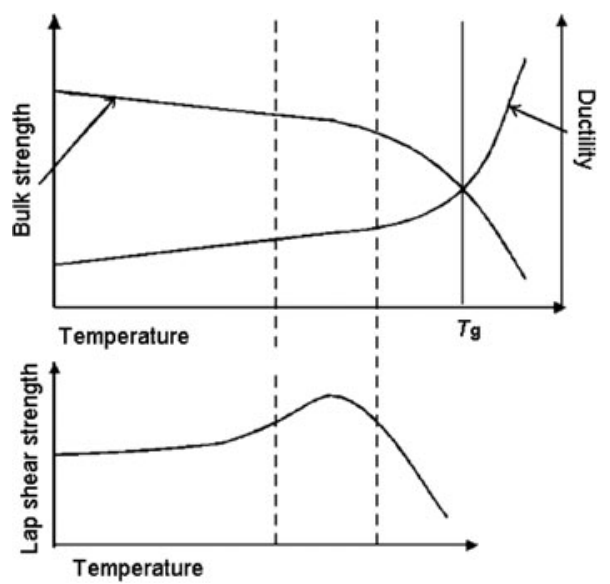

Figure 10. Lap shear strength behaviour as a function of adhesive ductility and bulk strength. 
(above $T_{\mathrm{g}}$ ). At $T_{\mathrm{g}}$, there was a drop in the elastic modulus as well as in the strength. Below $T_{\mathrm{g}}$, it was difficult to say at what temperature the lap shear strength was higher as there were two factors to consider: the ductility and the strength. Figure 10 shows schematically the lap shear strength behaviour as a function of the adhesive bulk properties. The lap shear strength increased with the adhesive ductility up to the best compromise between the ductility and the bulk strength. According to Figure 9, the temperature corresponding to the best strength/ductility combination for XN1244 adhesive was the $125^{\circ} \mathrm{C}$.

At temperatures above $T_{\mathrm{g}}$, the lap shear strength of the adhesive joints tested at $175^{\circ} \mathrm{C}$ was approximately $54 \%$ less than that of the specimens tested at RT, while data obtained from tests at $200^{\circ} \mathrm{C}$ showed a decrease in the lap shear strength of the adhesive joints by approximately $75 \%$.

The variation in the test results (see standard deviations at 175 and $200{ }^{\circ} \mathrm{C}$ in Figure 9) increased at temperatures above $T_{\mathrm{g}}$, because the adhesive properties had a sharp decrease making the joint behaviour very sensitive to small temperature changes in this range.

The adhesive deformation to failure increased with increasing temperature up to $150^{\circ} \mathrm{C}$ by approximately $23 \%$ at $100{ }^{\circ} \mathrm{C}, 53 \%$ at $125^{\circ} \mathrm{C}$ and $32 \%$ at $150{ }^{\circ} \mathrm{C}$, while at temperatures above $T_{\mathrm{g}}\left(175\right.$ and $\left.200^{\circ} \mathrm{C}\right)$ the adhesive deformation to failure decreased by approximately 19 and $51 \%$, respectively.

\section{Numerical analysis}

A non-linear geometrical numerical analysis was performed using the commercial finite element (FE) programme ABAQUS ${ }^{\circledR}$. The mesh used for the SLJs can be seen in Figure 11. Restraining and loading conditions are shown in Figure 6, consisting in clamping the joint at one of its edges and applying a vertical restraint and tensile displacement at the opposite edge, to faithfully reproduce the test conditions [28,29]. The joint was meshed by ABAQUS ${ }^{\circledR}$ CAE meshing algorithms from the user introduced seeding preferences (including bias effects). The mesh was particularly refined at the overlap edges to accurately capture spots of stress concentrations [30,31]. The joints were modelled as two-dimensional, with plane strain solid elements (referenced as CPE8 from the ABAQUS® library).

\subsection{Cohesive zone modelling}

Cohesive zone models (CZMs) model the elastic loading, initiation of damage and further propagation due to local failure within a material. CZMs are based on a relationship between stresses and relative displacements connecting initially superimposed nodes of the cohesive elements (Figure 12), to simulate the elastic behaviour up to the peak load and subsequent softening, to model the gradual degradation of material properties up to complete failure. Generically speaking, the shape of the softening laws can be adjusted to conform to the behaviour of the material or interface they were simulating [32,33]. The areas under the traction-separation laws in each mode of loading (tension and shear) were equalled to the respec-

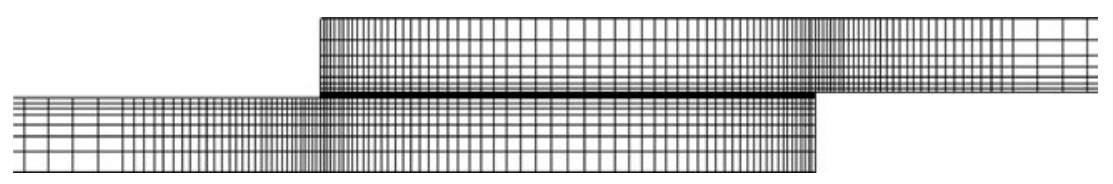

Figure 11. Finite element mesh used for an SLJ. 


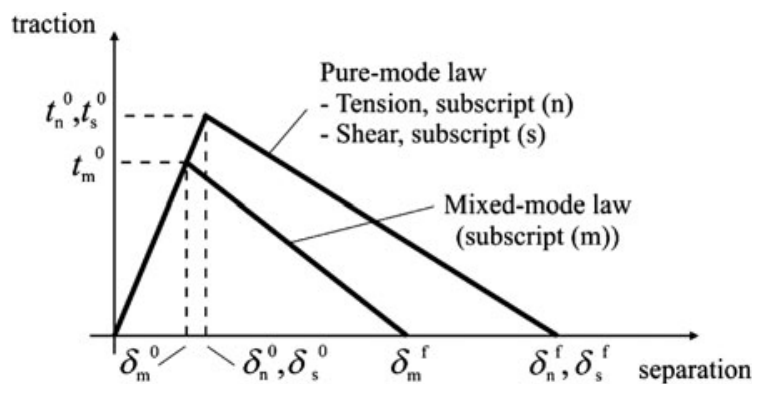

Figure 12. Traction-separation law with linear softening available in ABAQUS®.

tive fracture energy. Under pure mode, damage propagation occured at a specific integration point when the stresses were released in the respective traction-separation law. Under mixed mode, energetic criteria were often used to combine tension and shear [32], thus simulating the typical mixed-mode behaviour inherent to bonded assemblies. In this work, a continuumbased approach was considered to model the finite thickness of the adhesive layer. The cohesive layer was assumed to be under one direct component of strain (through thickness) and one transverse shear strain, which were computed directly from the element kinematics. The membrane strains were assumed as zero, which was appropriate for thin and compliant layers between stiff adherends. The traction-separation law assumes an initial linear elastic behaviour followed by linear evolution of damage. Elasticity is defined by an elastic constitutive matrix relating stresses and strains across the interface [34] as:

$$
t=\left\{\begin{array}{c}
t_{\mathrm{n}} \\
t_{\mathrm{s}}
\end{array}\right\}=\left[\begin{array}{cc}
K_{\mathrm{nn}} & K_{\mathrm{ns}} \\
K_{\mathrm{ns}} & K_{\mathrm{ss}}
\end{array}\right]\left\{\begin{array}{c}
\varepsilon_{\mathrm{n}} \\
\varepsilon_{\mathrm{s}}
\end{array}\right\}=K \varepsilon .
$$

The matrix $K$ contains the stiffness parameters of the adhesive layer, given by the quotient between the relevant elastic modulus and adhesive thickness $\left(t_{\mathrm{A}}\right)$. A suitable approximation for thin adhesive layers was provided with $K_{\mathrm{nn}}=E, K_{\mathrm{ss}}=G, K_{\mathrm{ns}}=0$, where $E$ and $G$ are the longitudinal and transverse elastic moduli [32]. Damage initiation can be specified by different criteria. In this work, the quadratic nominal stress criterion was considered for the initiation of damage, already shown to give accurate results [32], expressed as [34]

$$
\left\{\frac{\left\langle t_{\mathrm{n}}\right\rangle}{t_{\mathrm{n}}^{0}}\right\}^{2}+\left\{\frac{t_{\mathrm{s}}}{t_{\mathrm{s}}^{0}}\right\}^{2}=1 .
$$

where $t_{\mathrm{n}}^{0}$ and $t_{\mathrm{s}}^{0}$ represent the pure mode (normal or shear, respectively) peak values of the nominal stress. \langle\rangle are the Macaulay brackets, emphasizing that a purely compressive stress state does not initiate damage. After the peak value in Figure 12 was attained, the material stiffness was degraded under different possible laws, depending on the material to be simulated. For brittle materials such as XN1244 adhesive, a linear softening law was sufficiently appropriate [35]. Complete separation was predicted by a linear power law form of the required energies for failure in the pure modes [34]

$$
\frac{G_{\mathrm{n}}}{G_{\mathrm{n}}^{\mathrm{c}}}+\frac{G_{\mathrm{s}}}{G_{\mathrm{s}}^{\mathrm{c}}}=1 .
$$


The quantities $G_{\mathrm{n}}$ and $G_{\mathrm{s}}$ relate to the work done by the traction and corresponding relative displacements in the normal and shear directions, whilst the relating critical fracture energies required for pure mode failure are given by $G_{\mathrm{n}}^{\mathrm{c}}$ and $G_{\mathrm{s}}^{\mathrm{c}}$ for normal and shear loadings, respectively.

\section{Numerical results}

In the simulations, by modelling the adhesive layer as a traction-separation law with CZM and the adherends as elastic perfectly plastic using the approximation of Figure 4, fracture occurred due to cohesive crack propagation in the adhesive bond, beginning at the overlap edges with fast propagation to the inner regions of the bond.

The parameters $G_{\mathrm{n}}^{\mathrm{c}}$ and $G_{\mathrm{s}}^{\mathrm{c}}$ (the fracture toughness in pure mode I and II) were defined by testing at each temperature, with the DCB tests and the end-notched flexure (ENF) tests, respectively, in previous studies $[18,19,36]$. The $t_{\mathrm{n}}^{0}$ (normal cohesive stress) was determined from tensile bulk tests as a function of temperature [19], while $t_{\mathrm{s}}^{0}$ (shear cohesive stress) at RT, 100 and $150{ }^{\circ} \mathrm{C}$, was extracted by comparing numerical predictions from cohesive zone simulations to the results of ENF experimental tests [36].

It is known that for ductile adhesives the average lap shear stress in the joints at failure in quasi-static loading is very similar to the measured shear strength with the TAST. Actually, in a previous work [5], the authors found for Sikaflex 552 adhesive (supplied by Sika Portugal) that the TAST gave a $\tau_{\mathrm{r}}=2.39 \mathrm{MPa}$, while from SLJs tests the results were very similar $\left(\tau_{\mathrm{av}}=2.27 \mathrm{MPa}\right)$. This indicated that the shear stresses in the joints with ductile adhesives were uniformly distributed whether TAST or SLJ specimens were used. In other words, the SLJ can be used to determine the shear strength of ductile adhesives, contrarily to stiff and rigid adhesives. Therefore, at $200^{\circ} \mathrm{C}$, the $t_{\mathrm{s}}^{0}$ was estimated from the SLJs experiments, as it was not possible to determine it with the inverse method [36]. The material properties used for the CZM simulations are listed in Table 2.

In Figure 13, representative experimental and numerical load-displacement curves for the SLJ specimens at RT (a) 100 (b), 150 (c) $200^{\circ} \mathrm{C}$ and (d) can be seen.

At RT, the failure load predicted by the CZM was around $25 \%$ higher than the experimental failure load. One factor that explained the errors in predictions was the residual stresses. When adhesive joints are cured at high temperature and then cooled to RT, residual stresses will inevitably be present (the brittle adhesive XN1244 used in this study cures at high temperature $\left.\left[140^{\circ} \mathrm{C}\right]\right)$. These stresses can arise either from differential thermal shrinkage between the components of the specimen or from chemical shrinkage of the adhesive. When a crack grows in a specimen with residual stresses, the residual stresses can contribute to the total amount of energy released. On the other hand, it has been previously noted that the FE model predictions tend to be stiffer than the measured joint responses [37].

Table 2. Properties of XN1244 adhesive for CZM modelling.

\begin{tabular}{lcccccc}
\hline Temperature $\left({ }^{\circ} \mathrm{C}\right)$ & $G_{\mathrm{n}}^{\mathrm{c}}(\mathrm{N} / \mathrm{mm})$ & $G_{\mathrm{s}}^{\mathrm{c}}(\mathrm{N} / \mathrm{mm})$ & $t_{\mathrm{n}}^{0}(\mathrm{MPa})$ & $t_{\mathrm{s}}^{0}(\mathrm{MPa})$ & $E(\mathrm{MPa})$ & $G(\mathrm{MPa})$ \\
\hline $\mathrm{RT}$ & 0.47 & 2.2 & 68 & 32 & 5872 & 2150 \\
100 & 0.50 & 2.6 & 45 & 25 & 4173 & 1527 \\
150 & 0.42 & 1.7 & 6.5 & 12 & 72 & 25 \\
200 & 0.07 & 0.3 & 1.4 & 3 & 40 & 14.6 \\
\hline
\end{tabular}




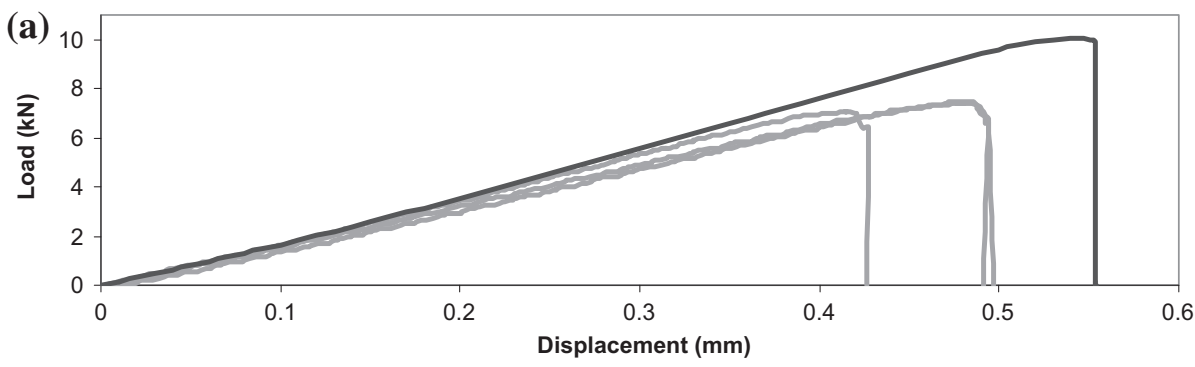

Experimental Numerical

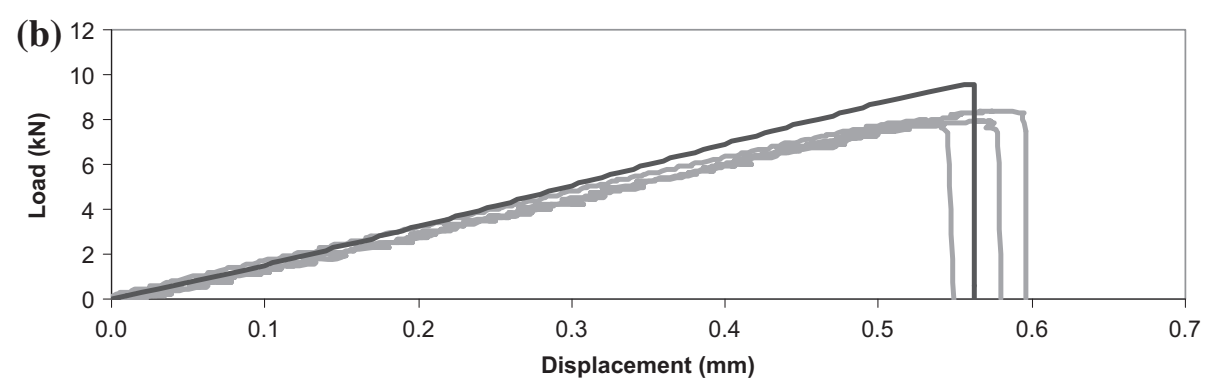

Experimental Numerical
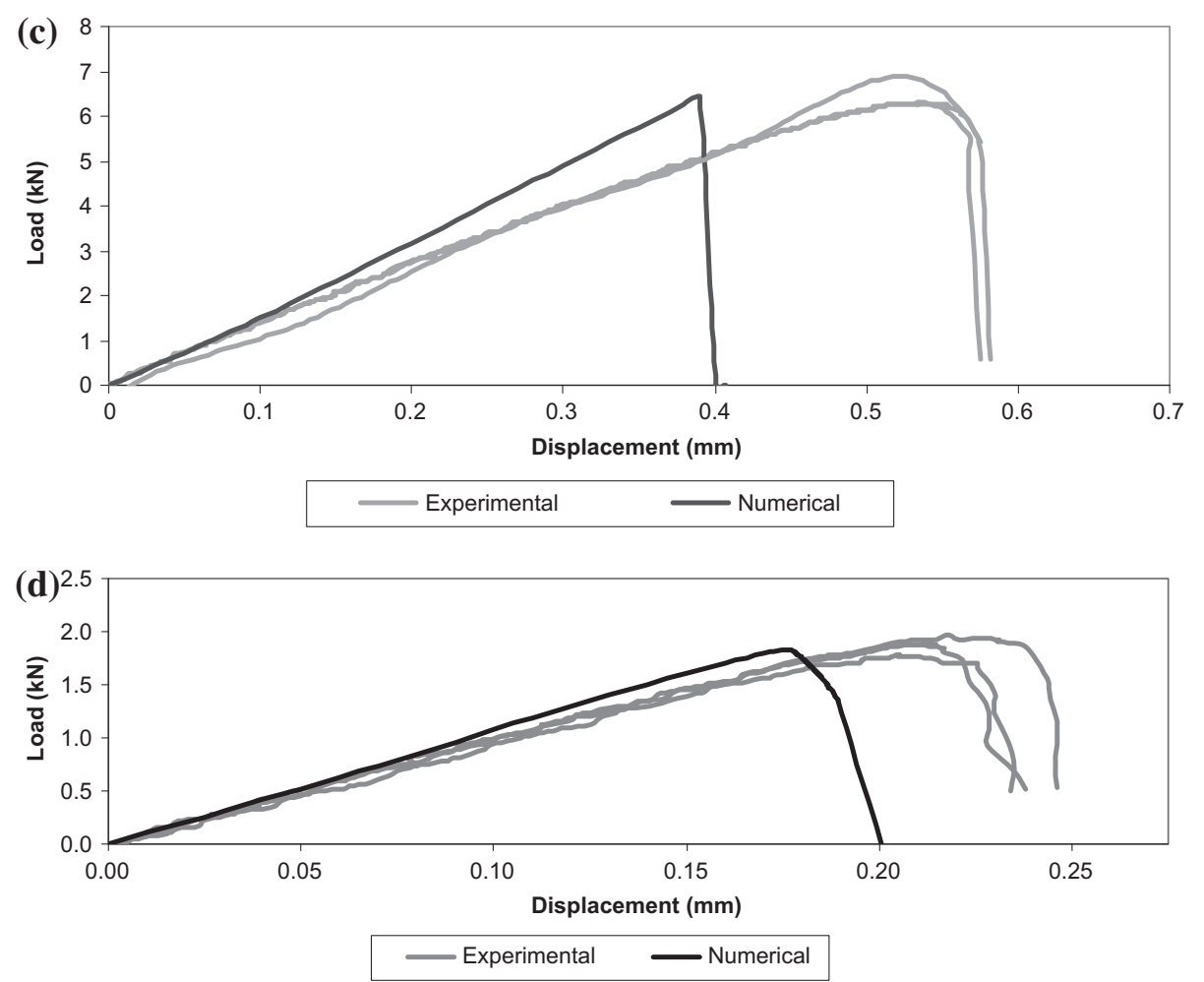

Figure 13. Representative experimental and numerical $P-\delta$ curves at (a) RT, (b) 100, (c) 150 and (d) $200{ }^{\circ} \mathrm{C}$. 
The simulation response matched the experimental results well at $100{ }^{\circ} \mathrm{C}$. At 150 and $200{ }^{\circ} \mathrm{C}$ (temperatures close and above $T_{\mathrm{g}}$ ), the simulation response matched the experimental results reasonably well. However, the displacement at fracture was not well captured. The fracture in the model occurs well before the displacement where fracture occurred in the experiment. It seems that some mechanism of failure was not captured by the CZM at these temperatures.

As we have seen before, with the increased temperature close to $T_{\mathrm{g}}$, the ductility of the adhesive increased. Hence, even though several authors showed that the shape of the traction-separation law was relatively unimportant to the outcome of the models [38-40], the trapezoidal traction-separation law, to model the adhesive at $150{ }^{\circ} \mathrm{C}$, might be more appropriate to be used as it accounts for large plasticization up to failure occurring under these conditions. Nevertheless, while the bilinear traction-separation law was readily available in $A B A Q U S \circledR$, the trapezoidal traction-separation law has not yet been implemented; hence, the trapezoidal model needed special subroutines in ABAQUS® and was more difficult to use. On the other hand, at temperatures above $T_{\mathrm{g}}$ (at $200^{\circ} \mathrm{C}$ ), some uncertainties about the state of chemical degradation of the adhesive existed. However, further investigations on the use of these laws at temperatures close to and above $T_{\mathrm{g}}$ are needed.

\section{Conclusions}

The main objective of this work was to evaluate the capabilities of using the current implementations of CZM available in ABAQUS ${ }^{\circledR}$ to simulate the behaviour and strength of adhesively bonded joints as a function of temperature and validate experimentally the damage laws for pure mode I and pure mode II, determined in previous studies. For this purpose, SLJs between aluminium adherends were fabricated and tested at RT and high temperatures. The following conclusions can be drawn:

- At temperatures below $T_{\mathrm{g}}$, the lap shear strength of SLJs increased (by approximately $9 \%$ at $100{ }^{\circ} \mathrm{C}$ and by $30 \%$ at $125^{\circ} \mathrm{C}$ ), while at temperatures above $T_{\mathrm{g}}$, a drastic drop in the lap shear strength was observed (by $54 \%$ at $175^{\circ} \mathrm{C}$ and by approximately $75 \%$ at $\left.200^{\circ} \mathrm{C}\right)$.

- The lap shear strength increased with the adhesive ductility up to the best compromise between the ductility and the bulk strength. The temperature corresponding to the best strength/ductility combination for the specific aluminium SLJ bonded with XN1244 adhesive was the $125^{\circ} \mathrm{C}$.

- CZMs have been used to characterize the adhesive behaviour as a function of temperature. The simulation response for various temperatures matches reasonably well the experimental results.

\section{Acknowledgements}

The authors would like to thank the Portuguese Foundation for Science and Technology for supporting the work presented here, through the individual grant SFRH/BD/61880/2009 and through the research project PTDC/EME-PME/67022/2006, and Nagase ChemteX (Japan) for supplying the adhesive.

\section{References}

[1] Lu D, Wong CP. Effects of shrinkage on conductivity of isotropic conductive adhesives. International Journal of Adhesion and Adhesives. 2000;20:189-93. 
[2] da Silva LFM, Adams RD. Stress-free temperature in a mixed-adhesive joint. International Journal of Adhesion and Adhesives. 2006;20:1705-26.

[3] Adams RD, Mallick V. The effect of temperature on the strength of adhesively-bonded compositealuminum joints. Journal of Adhesion. 1993;43:17-33.

[4] da Silva LFM, Adams RD. Adhesive joints at high and low temperatures using similar and dissimilar adherends and dual adhesives. International Journal of Adhesion and Adhesives. 2007;27:216-26.

[5] Banea MD, da Silva LFM. The effect of temperature on the mechanical properties of adhesives for the automotive industry. Proceedings of the IMechE, Part L: Journal of Materials: Design and Applications. 2010;224:51-62.

[6] da Silva LFM, Adams RD. Measurement of the mechanical properties of structural adhesives in tension and shear over a wide range of temperatures. Journal of Adhesion Science and Technology. 2005;19:109-41.

[7] Chiu WK, Chalkley PD, Jones R. Effects of temperature on the shear stress-strain behaviour of structural adhesives (FM73). Computers and Structures. 1994;53:483-9.

[8] Banea MD, da Silva LFM. Static and fatigue behaviour of room temperature vulcanizing silicone adhesives for high temperature aerospace applications. Materialwissenschaft und Werkstofftechnik. 2010;41:325-35.

[9] Deb A, Malvade I, Biswas P, Schroeder J. An experimental and analytical study of the mechanical behaviour of adhesively bonded joints for variable extension rates and temperatures. International Journal of Adhesion and Adhesives. 2008;28:1-15.

[10] Adams RD, Coppendale J, Mallick V, Al-Hamdan H. The effect of temperature on the strength of adhesive joints. International Journal of Adhesion and Adhesives. 1992;12:185-90.

[11] Kang SG, Kim MG, Kim CG. Evaluation of cryogenic performance of adhesives using compositealuminum double-lap joints. Composite Structures. 2007;78:440-6.

[12] Banea MD, da Silva LFM. Mechanical characterization of flexible adhesives. Journal of Adhesion. 2009;85:261-85.

[13] Srivastava VK. Characterization of adhesive bonded lap joints of C/C-SiC composite and Ti-6Al$4 \mathrm{~V}$ alloy under varying conditions. International Journal of Adhesion and Adhesives. 2003;23:59-67.

[14] Grant LDR, Adams RD, da Silva LFM. Effect of the temperature on the strength of adhesively bonded single lap and $\mathrm{T}$ joints for the automotive industry. International Journal of Adhesion and Adhesives. 2009;29:535-42.

[15] Banea MD, de Sousa FSM, da Silva LFM, Campilho RDSG, de Bastos Pereira AM. Effects of temperature and loading rate on the mechanical properties of a high temperature epoxy adhesive. Journal of Adhesion Science and Technology. 2011;25:2461-74.

[16] Melcher RJ, Johnson WS. Mode I fracture toughness of an adhesively bonded composite-composite joint in a cryogenic environment. Composites Science and Technology. 2007;67:501-6.

[17] Banea MD, da Silva LFM, Campilho RDSG. Temperature dependence of the fracture toughness of adhesively bonded joints. Journal of Adhesion Science and Technology. 2010;24:2011-26.

[18] Banea MD, da Silva LFM, Campilho RDSG. Mode I fracture toughness of adhesively bonded joints as a function of temperature: experimental and numerical study. International Journal of Adhesion and Adhesives. 2011;31:273-9.

[19] Banea MD, da Silva LFM, Campilho RDSG. Effect of temperature on tensile strength and mode I fracture toughness of a high temperature epoxy adhesive. Journal of Adhesion Science and Technology. 2012;26:939-53.

[20] NF T 76-142. Méthode de preparation de plaques d'adhésifs structuraux pour la réalisation d'éprouvettes d'essai de caractérisation 1988.

[21] ISO 11003-2:1993(E). Adhesives - Determination of shear behavior of structural bonds, part II: Thick Adherend Tensile Test method, 1993. 
[22] da Silva LFM, Silva RAM, Chousal JAG, Pinto AMG. Alternative methods to measure the adhesive shear displacement in the thick adherend shear test. Journal of Adhesion Science and Technology. 2008;22:15-29.

[23] Chousal JAG, Gomes JF. Image processing aided shearography-processing correlation. In: Proceedings M2D, 3rd International Conference on Mechanics \& Materials in Design, Orlando, FL, 2000.

[24] ASTM-E8M-04. Standard test methods for tension testing of metallic materials, 2004.

[25] Campilho RDSG, Banea MD, Pinto AMG, da Silva LFM, de Jesus AMP. Strength prediction of single and double-lap joints by standard and extended finite element modelling. International Journal of Adhesion and Adhesives. 2011;31:363-72.

[26] Zhao X, Adams RD, da Silva LFM. Single lap joints with rounded adherend corners: experimental results and strength prediction. Journal of Adhesion Science and Technology. 2011;25:837-56.

[27] da Silva LFM, Adams RD, Gibbs M. Manufacture of adhesive joints and bulk specimens with high-temperature adhesives. International Journal of Adhesion and Adhesives. 2004;24:69-83.

[28] Campilho RDSG, de Moura MFSF, Ramantani DA, Morais JJL, Domingues JJMS. Tensile behaviour of three-dimensional carbon-epoxy adhesively bonded single- and double-strap repairs. International Journal of Adhesion and Adhesives. 2009;29:678-86.

[29] Campilho RDSG, de Moura MFSF, Domingues JJMS, Morais JJL. Computational modelling of the residual strength of repaired composite laminates using a cohesive damage model. Journal of Adhesion Science and Technology. 2008;22:1565-91.

[30] Campilho RDSG, de Moura MFSF, Domingues JJMS. Modelling single and double-lap repairs on composite materials. Composites Science and Technology. 2005;65:1948-58.

[31] Campilho RDSG, de Moura MFSF, Barreto AMJP, Morais JJL, Domingues JJMS. Fracture behaviour of damaged wood beams repaired with an adhesively-bonded composite patch. Composites: Part A. 2009;40:852-9.

[32] Campilho RDSG, de Moura MFSF, Domingues JJMS. Using a cohesive damage model to predict the tensile behaviour of CFRP single-strap repairs. International Journal of Solids and Structures. 2008;45:1497-512.

[33] Campilho RDSG, de Moura MFSF, Pinto AMG, Morais JJL, Domingues JJMS. Modelling the tensile fracture behaviour of CFRP scarf repairs. Composites Part B. 2009;40:149-57.

[34] ABAQUS® HTML Documentation, Dassault Systemes, 2009.

[35] Alfano G. On the influence of the shape of the interface law on the application of cohesive-zone models. Composites Science and Technology. 2006;66:723-30.

[36] Banea MD, da Silva LFM, Campilho RDSG. Mode II fracture toughness of adhesively bonded joints as a function of temperature: experimental and numerical study. Journal of Adhesion. 2012;88:534-51.

[37] Duncan B, Crocker L, Urquhart J, Arranz E, Mera R, Broughton B. Failure of flexible adhesive joints, Report no. 5, NPL Report MATC(A)36 Middlesex, UK, 2001.

[38] Gustafson PA, Waas AM. The influence of adhesive constitutive parameters in cohesive zone finite element models of adhesively bonded joints. International Journal of Adhesion and Adhesives. 2009;46:2201-15.

[39] Xie D, Waas AM. Discrete cohesive zone model for mixed-mode fracture using finite element analysis. Engineering Fracture Mechanics. 2006;73:1783-96.

[40] Mohammed I, Liechti KM. Cohesive zone modeling of crack nucleation at bimaterial corners. Journal of the Mechanics and Physics of Solids. 2000;48:735-64. 